University of Nebraska - Lincoln

DigitalCommons@University of Nebraska - Lincoln

2005

\title{
An Evaluation of Weather and Disease as Causes of Decline in Two Populations of Boreal Toads
}

Rick D. Scherer

Erin Muths

USGS, muthse@usgs.gov

Barry R. Noon

Paul Stephen Corn

Follow this and additional works at: https://digitalcommons.unl.edu/usgsstaffpub

Part of the Earth Sciences Commons

Scherer, Rick D.; Muths, Erin; Noon, Barry R.; and Corn, Paul Stephen, "An Evaluation of Weather and Disease as Causes of Decline in Two Populations of Boreal Toads" (2005). USGS Staff -- Published Research. 109.

https://digitalcommons.unl.edu/usgsstaffpub/109

This Article is brought to you for free and open access by the US Geological Survey at DigitalCommons@University of Nebraska - Lincoln. It has been accepted for inclusion in USGS Staff -- Published Research by an authorized administrator of DigitalCommons@University of Nebraska - Lincoln. 


\title{
AN EVALUATION OF WEATHER AND DISEASE AS CAUSES OF DECLINE IN TWO POPULATIONS OF BOREAL TOADS
}

\author{
Rick D. Scherer., ${ }^{1.4}$ Erin Muths, ${ }^{2}$ Barry $R$. NoOn, ${ }^{1}$ and Paul Stephen Corn ${ }^{3}$ \\ 'Colorado State University, Department of Fishery and Wildife Biology, Wagar Building 136 , \\ Fort Collins, Colorado 80523-1474 USA \\ 2U.S. Geological Survey Fort Collins Science Center, 2150 Centre Avenue, Bldg C \\ Fort Collins, Colorado 80526-8118 USA \\ ${ }^{3}$ U.S. Geological Survey Northern Rocky Mountain Science Center, Aldo Leopold Wilderness Research Institute. \\ P.O. Box 8089. Missoula. Montana 59807 USA
}

\begin{abstract}
Two populations of boreal toads (Bufo boreas) experienced drastic declines in abundance in the late 1990s. Evidence supported the hypothesis of disease (the chytrid fungus, Batrachochytrium dendrobatidis) as the cause of these declines, but other hypotheses had not been evaluated. We used an 11-year capture-recapture data set to evaluate weather and disease as causes of these declines. We developed sets of mathematical models that reflected hypothesized relationships between several weather variables and annual survival rates of adult males in these populations. In addition, models that reflected the possibility that the declines were caused by an introduced fungus were developed. All models were fit to the data and were evaluated using a model selection criterion (QAIC $)_{c}$. Our analysis provided strong support for the hypothesis of an introduced fungus and little support for the hypothesis that weather conditions caused the declines. Our results also suggest a strong, negative "marking effect" on survival rates of boreal toads. Modelaveraged estimates of survival rate are presented.

Key words: amphibian declines; Batrachochytrium dendrobatidis; boreal toads; Bufo boreas; capture-recapture; chytrid fungus; demographic parameters; marking effect; model selection; weather; wildlife disease.
\end{abstract}

\section{INTRODUCTION}

Evidence suggests that declines in amphibian populations have been occurring for decades (Houlahan et al. 2000), but concern over this phenomenon has recently increased. Reductions in distribution, declines in population size, and extinctions have been documented in species of amphibians from around the world. Amphibians are more threatened and may be declining more rapidly than either birds or mammals (Stuart et al. 2004). The causes of many amphibian declines are not well understood; thus, implementation of effective management and conservation actions is often hindered (Stuart et al. 2004).

The populations of boreal toads (Bufo boreas) at Kettle Tarn (KT) and Lost Lake (LL) in Rocky Mountain National Park (RMNP), Colorado, USA (see Muths et al. [2003] for descriptions of these sites) have experienced recent declines in abundance and appear to be approaching extinction (Muths et al. 2003). The cause of these declines is not known, but some explanatory hypotheses have been evaluated using data from these sites and other nearby locations (e.g., habitat acidification [Corn and Vertucci 1992], UV-B radiation [Corn 1998], and environmental variables such as tem-

Manuscript received 15 March 2005; accepted 25 March 2005 Corresponding Editor: J. Van Buskirk.

${ }^{4}$ E-mail: scherer@icnr.colostate.edu perature, precipitation, and UV-B radiation [Carey et al. 2001]). Recently, a chytrid fungus (Batrachochytrium dendrobatidis, hereafter referred to as $B . d$.), was identified on live and dead boreal toads collected from 1998 to 2000 from KT and LL (Muths et al. 2003). This fungus has been implicated in mass mortality events associated with amphibian population declines and extinctions (Berger et al. 1998. Green and Kagarise-Sherman 2001), and genetic and ecological evidence suggest that $B . d$. has been introduced recently into amphibian populations in many countries (Daszak et al. 1999, Morehouse et al. 2003). Muths et al. (2003) presented three lines of evidence in support of the hypothesis that the cause of the declines at $\mathrm{KT}$ and $\mathrm{LL}$ is B.d. First, they reported histological findings that suggested $B . d$. was the cause of death in six dead and dying toads from KT and LL. Second, they cited the temporal correlation between the detection of $B . d$. and declines in these amphibian populations. Third, they noted the similarity in epizootiological features between these declines and other declines attributed to the fungus. The strength of this evidence is difficult to characterize because other possible causes of these declines (e.g., weather) have not been evaluated using data from these sites.

The populations at KT and LL have been sampled annually, starting in 1991, using capture-recapture methods. These data offer a rare opportunity to study 
the temporal and spatial variability in the demographic parameters of declining amphibian populations. We used the existing capture-recapture data sets from the $\mathrm{KT}$ and LL populations to address the following questions: (1) What variable or set of variables (i.e., model) provides the most parsimonious description of the temporal and spatial variation in estimates of annual survival rates of adult males? (2) What does the structure of that model suggest about the cause of the declines in boreal toads at KT and LL? Based on the literature on amphibian declines and the ecology of $B$. boreas and $B . d$, we developed a priori hypotheses that relate annual survival rates of adult, male boreal toads to several weather variables. In addition. we developed a priori hypotheses that reflect the possibility that the declines were caused by introduced $B . d$. Only the adult, male segment of these populations was examined. because data on females and juveniles are too sparse.

\section{BACKGROUND INFORMATION FOR MODEL SPECIFICATION}

In the following sections, we present the background information that we used in specification of the models evaluated in this analysis (i.e., the candidate set of models; Burnham and Anderson 1998).

\section{Models with weather variables}

To facilitate identification of weather variables that would be incorporated into models of annual survival rate, the annual activity cycle for boreal toads was divided into two periods: the winter hibernation period and the growing season (the rest of the year when toads are active above ground). The ecological rationale for inclusion of each of the weather variables will be described. Additional information on the ecology of $B u f o$ boreas and B.d. that supports inclusion of the weather variables can be found in Longcore et al. (1999), Scherer (2004), and Carey et al. (2005).

Weather variables for survival over the hibernation period.-Boreal toads use terrestrial hibernacula and cannot tolerate freezing body tissue (Hammerson 1999). Thus, toads may be vulnerable to freezing during unusually cold winters. Two covariates were developed to examine the hypothesis that air temperatures affect survival during the hibernation period: " $T_{\min }$ coldest 7 days" and "Hibernation mean $T_{\min }$ " (see Table 1 for a list of the weather variables examined in this paper and the Appendix for a complete description of each weather covariate)

Campbell (1970) suggested that snow cover and flowing groundwater protect hibernating boreal toads from freezing and desiccation. To evaluate the possible impact of snow depth and groundwater on survival, five covariates were developed: "Snowpack," "Snowpack 1st day," "1st day sustained snow," "Hibernation 12 precipitation," and "Hibernation 32 precipitation."

Weather variables for survival over the growing season.-Amphibians have thin, highly permeable skin
TABLE 1. The climatic covariates evaluated in the analysis of survival rates and their expected relationship to survival rate.

\begin{tabular}{ll}
\hline \hline \multicolumn{1}{c}{ Variable name } & $\begin{array}{c}\text { Expected relationship } \\
\text { to survival rate }\end{array}$ \\
\hline $\mathrm{T}_{\text {mir }}$ coldest 7 days & positive \\
Hibernation mean $\mathrm{T}_{\text {min }}$ & positive \\
Snowpack & positive \\
Snowpack 1 st day & positive \\
1st day sustained snow & negative \\
Hibernation 12 precipitation & positive \\
Hibernation 32 precipitation & positive \\
Growing 12 precipitation & positive/negative \\
Growing 32 precipitation & positive/negative \\
$\mathrm{T}_{\text {max }}$ warmest 7 days & positive/negative \\
Growing mean $\mathrm{T}_{\text {max }}$ & positive/negative \\
Growing mean $\mathrm{T}_{\text {ave }}$ & positive/negative \\
Growing season length & positive \\
\hline
\end{tabular}

that plays an important role in hydration and gas exchange (Duellman and Trueb 1994). Xeric conditions could cause reduced survival rates as toads are more prone to dehydration or inhibited gas exchange. Additionally, reduced survival rates during xeric times could be the consequence of increased transmission rates of chytrid fungus as toads become more densely aggregated around remaining sources of moisture (Pounds et al. 1999). However, xeric conditions could also lead to higher survival rates as movement of the chytrid zoospores may be inhibited and transmission rates reduced (Daszak et al. 1999). Two covariates were developed to examine the possibility that survival rates are correlated with the amount of available moisture in the environment: "Growing 12 precipitation" and "Growing 32 precipitation."

Although it is unlikely that summer air temperatures alone are a threat to adult amphibians (Duellman and Trueb 1994), relatively warm summer temperatures combined with xeric conditions could cause reduced survival rates as individuals are more susceptible to desiccation. In addition, air temperature during the growing season may affect chytrid fungus virulence (Berger et al. 2004). Higher air temperatures may inhibit chytrid fungus growth (Longcore et al. 1999) and reduce the impact of the fungus on its amphibian host. To evaluate possible relationships between air temperature during the growing season and boreal toad survival rate, three covariates were developed: " $T_{\max }$ warmest 7 days," "Growing mean $T_{\text {max }}$ ", and "Growing mean $T_{\text {ave }}$."

Finally, a measure of the length of the growing season is of interest. From the time that toads leave winter hibernacula in spring until they enter hibernacula in the fall, they must obtain sufficient energetic resources to sustain basic metabolism, grow, reproduce, and survive the next hibernation period (Carey et al. 2005). Populations of prey species may be less abundant and less active during short, cool growing seasons, and these conditions could minimize the rates of physio- 
logical processes related to energy acquisition and assimilation in toads. One covariate, "Growing season length," was developed to examine the possibility that survival rate was affected by the length of the active season.

\section{Introduced disease models}

Ideally, models to test the disease hypothesis would incorporate one of the following covariates: the year(s) when B.d. was introduced into these populations, annual infection rate(s) in each of the populations, or the infection status of individual toads in the populations. Data on the presence of $B . d$. in the populations at KT and LL are sparse, because the emergence of $B . d$. as an important factor in amphibian declines was not reported until 1998 (Berger et al. 1998). Between 1998 and 2000,12 dead boreal toads were observed at $\mathrm{KT}$ and LL and were submitted for examination (Muths et al. 2003). B.d. was detected on all of the specimens that were adequately preserved $(n=6)$ and appeared to be the cause of death (Muths et al. 2003). Thus, the presence of B.d. was confirmed in 1998 (Muths et al. 2003), but it is not known if the fungus was present prior to 1998. Similarly, annual infection rates in the two populations and the infection status of individuals in each population are not known. However, relevant models that represent the hypothesis of introduced $B . d$. as the cause of the declines can be developed. We used information from the long-term presence of researchers at these sites, reports from other amphibian population declines attributed to $B . d$. laboratory studies of the effect of $B . d$. on amphibians, and epidemiological theory to develop these models.

Several researchers have reported mass die-offs and extinctions over short temporal scales in amphibian populations in which B.d. has been detected (e.g., Berger et al. 1998, Lips 1999). Both observations suggest drastically reduced survival rates. In an infected population of postmetamorphic great barred frogs (Mixophyes fasciolatus), the mortality rate was estimated at $>90 \%$ (Berger et al. 1998). Although results of recent research suggest that air temperature may affect the virulence of $B . d$., nearly all postmetamorphic anurans exposed to at least 100 zoospores of $B . d$. in lab trials have contracted the disease and died (Berger et al. 1998, 1999, 2004, Longcore et al. 1999). In addition, retrospective examination of museum specimens found that $B . d$. was present on frogs collected during mass mortality events and absent from individuals collected only two years prior to the events (Berger et al. 1998). This information suggests that $B . d$. is a highly virulent pathogen of some amphibian species, and the temporal scale over which reductions in abundance occur can be short.

Information from two previous studies suggested that mass mortality events at KT and LL caused by B.d. may have occurred sometime from 1995 to 1998 . First, workers noted a decline in the size of breeding aggregations at these sites beginning in 1996 (Corn et al. 1997). If this reduction were the result of a mass mortality event caused by B.d., that event would have occurred prior to the breeding season in 1996 and would be reflected in the survival rates of 1995 . (The reduction could also be caused by lower detection probability and/or participation in breeding in 1996.) Second, the presence of $B . d$. was confirmed in 1998 (Muths et al. 2003). If $B$.d. were as virulent in these populations as has been reported in other anuran populations, a mass die-off would be expected to occur shortly thereafter (i.e., reductions in survival rates in these populations would be expected as soon as 1998). Thus, we developed models that confined possible die-off years (i.e., years of reduced survival rates) to 1995-1998. Additionally, it is possible that $B . d$. was introduced and caused die-offs in the populations at KT and LL in different years. Under a scenario of an introduced, highly virulent $B . d$., a decline in annual survival rate at KT may have occurred in 1995 and at LL in 1996 or in any other combination of the four years in the two populations. Therefore, we used 16 year $\times$ population combinations to model the year of the die-off under the hypothesis of introduced B.d.

Although the expected short-term response of the boreal toad populations to a highly virulent $B . d$. is reduced survival rate, we have relatively little empirical information with which to develop models of the longterm response of amphibian populations to the presence of B.d. S. M. Blomquist and M. J. Sredl (unpublished manuscript) reported evidence in 2001 that survival rates of Rana yavapaiensis returned to pre-decline levels following a die-off attributed to $B . d$. Based on this information, one can hypothesize an acute effect of $B . d$. on survival rates (i.e., survival rates drop to low levels during a die-off and then return to higher levels after the die-off; Fig. 1A). Daszak et al. (1999) discussed two possible mechanisms that could result in an acute effect of a pathogen on survival rates. First, the pathogen could cause reduced host densities, which might decrease the rate of transmission between individuals in the host populations. Those individuals that initially avoid infection have a lower probability of contracting the disease and. consequently, their survival rates would tend to be near background levels. The other possible mechanism is resistance. A portion of the host population may be resistant to the pathogen and their survival rates are expected to remain relatively high.

Alternatively, the response of an amphibian population to the presence of $B . d$. could be chronic depression of survival rates. Many populations that experience die-offs attributed to $B . d$. do not attain former levels of abundance or robustness (Green and Kagarise Sherman 2001), and a number of populations have been reported to be extinct (Berger et al. 1999). Based on this information, one can hypothesize a chronic effect of B.d. on survival rates (Fig. 1A). 


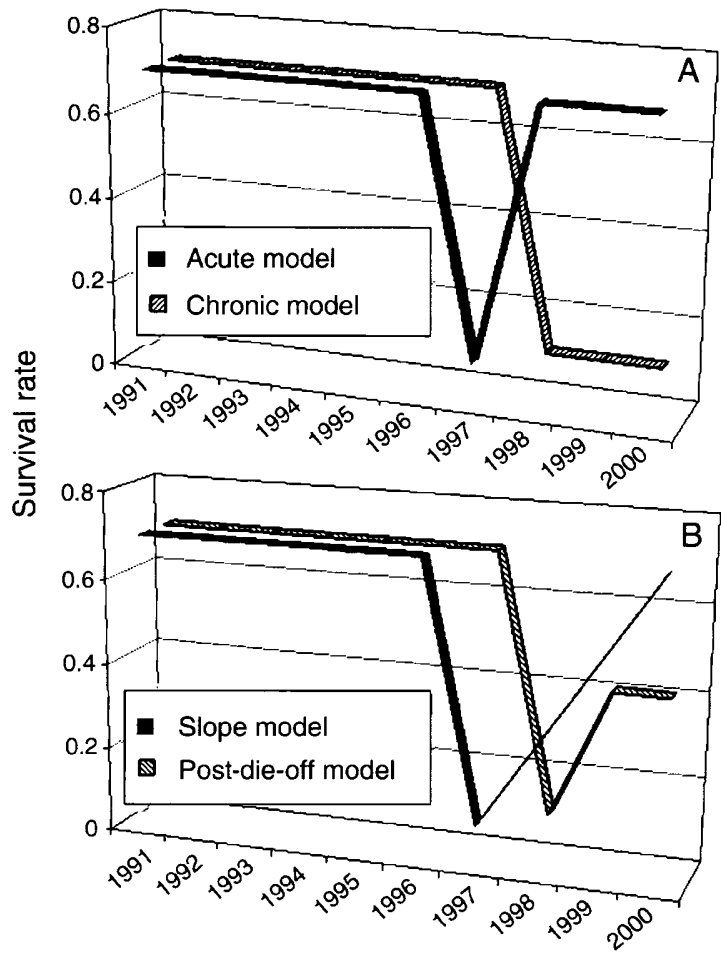

FIG. 1. Illustration of the general structure of the disease models of $\hat{\Phi}_{i}$. (A) Examples of the acute and chronic effect models from the a priori analysis of apparent survival rates. The acute effect example (black line) has the die-off year in 1997; the chronic effect example (hatched line) has the dieoff year in 1998. (B) Examples of the slope and post-die-off models from a subsequent a posteriori analysis of apparent survival rates: a sample slope effect model (black line) has the die-off year in 1997 and a sample post-die-off effect model (hatched line) has the die-off year in 1998. In both figures, survival rate is graphed on the $y$-axis. The scale of the $y$-axis is provided only for completeness and does not reflect estimated or expected apparent survival rates.

\section{Models of marking effect}

In addition to evaluating various models of decline, we used models to look for evidence of passive integrated transponder (PIT) tag loss and deleterious effects of marking (i.e., a marking effect) on survival rate. Few capture-recapture studies have looked for evidence of these problems (Murray and Fuller 2000), although there are occasional reports of PIT tag loss in the literature (e.g., Schooley et al. 1993; but see Brown 1997). Previously, authors have observed PIT tag loss shortly after implantation and have speculated that PIT tags exited out the holes that were created to insert them (Schooley et al. 1993).

\section{Models of capture probability}

We captured toads over multiple capture occasions within annual capture periods that roughly corresponded with the annual breeding period. Standard capturerecapture models (time-dependent and time $\times$ popu- lation models) were used in the analysis of capture probability. In addition, covariates were developed for three other models. First, annual capture probability was modeled as a function of the number of capture occasions in each year. All else being equal, capture probability is expected to increase as more capture occasions are conducted. Second, the number of capture occasions in each year was log-transformed to account for the possibility that the rate of increase in capture probability declined as the number of capture occasions increased. Third, capture probability was modeled as a function of the length of the previous active season. Because capture occasions were conducted during the breeding season, it is possible that only breeding males were present for capture in a particular year. Males that are not prepared to breed may not be present at breeding aggregations. Therefore, a higher proportion of males may be present at breeding sites in breeding seasons that follow long active seasons, and capture probabilities in those years may be higher.

\section{Methods \\ Capture-recapture models}

The Cormack-Jolly-Seber (CJS) model in Program MARK (White and Burnham 1999) was used to estimate annual survival rates (Lebreton et al. 1992). Two parameters make up the CIS model: apparent survival rate and capture probability. Apparent survival rate at interval $i$, denoted $\Phi_{l}$, is defined as the probability that a marked individual in the population during the sampling period at time $i$ survives and remains in the population until the sampling period at time $i+1$ (Williams et al. 2002). This parameter is referred to as apparent survival, because individuals that emigrate permanently from the population cannot be distinguished from animals that die (Williams et al. 2002). Unless the species under study shows high site fidelity, apparent survival rate equals 1 - (mortality rate + rate of permanent emigration). Capture-recapture studies for many species of pond-breeding amphibians, including Bufo boreas, suggest that site fidelity in adults is high (i.e., rate of permanent emigration $\cong 0$ [Olson 1992]). Thus, estimates of apparent survival rate from the CIS model may be more reflective of actual survival for these species. Capture probability at period $i$, denoted $p_{i}$, is defined as the probability that a marked individual in the population is captured during period $i$.

\section{Collection and preparation of capture and climate data}

Capture data-Beginning in 1991, capture data were collected throughout the 3-5 months that boreal toads were active at KT and LL. Most captures were made on sampling occasions during the breeding season. However, capture data were also collected during sampling occasions after the breeding season. This project used data only from individuals that were captured 
before and $<3$ weeks after the last egg mass was observed at each site. Thus, the length of the capture period was reduced to an average of 25 days (range 11-56 days).

During breeding-season capture occasions, 1-4 workers searched breeding sites (edges of all bodies of water and adjacent wetlands and terrestrial areas) and captured toads by hand. Each captured toad was checked for an existing passive integrated transponder (PIT tag) using an AVID reader (AVID, Folsum, Louisiana, USA). If the toad was already tagged, its identification number was recorded. If the toad was not tagged, a pair of scissors or an injector provided by AVID was used to insert a PIT tag. The incision was closed using a surgical adhesive. Captured toads were sexed and had their mass determined using a plastic bag and Pesola spring scale (Pesola, Baar. Switzerland). Snout-to-vent length (SVL) was measured using dial calipers (General Tools, New York, New York, USA).

Climate data.-In addition to capture-recapture data, weather data from nearby weather stations were used to evaluate the relationship between weather variation and observed declines in boreal toads at KT and LL (National Climatic Data Center; data available online). ${ }^{5}$ The Natural Resources Conservation Service in Colorado also provided weather data (available online). ${ }^{6}$ Data from six stations east of the Continental Divide, relatively near, and at comparable elevations to the two study sites were used (Appendix). The weather stations used for KT were $13-30 \mathrm{~km}$ away, whereas the weather stations used for LL were 15-53 $\mathrm{km}$ away. The process that we used to estimate weather values for $K T$ and $L L$ from weather station data is described in the Appendix.

\section{Development of models in the candidate set}

Candidate set of weather models.--.-Each of the weather covariates was incorporated into one or more mathematical models of $\Phi_{i}$ (see the Appendix for a complete list). All models that included climatic covariates were initially conceived in the form of a general linear model (Lebreton et al. 1992). To constrain estimates of $\Phi_{i}$ to between 0 and 1, we linked each of these linear models to $\Phi_{i}$ using the logit link function (Lebreton et al. 1992).

Candidate set of disease models.--For all of the a priori disease models, only two parameters are used to model $\Phi_{i}$. Years of relatively high $\Phi_{i}$ are expected prior to a die-off caused by $B . d$., whereas years of relatively low $\Phi_{i}$ are expected in the year of the die-off. In the models with an acute effect of B.d., $\Phi$; values return to pre-die-off levels in years subsequent to the year of the die-off (Fig. 1A). In the models with a chronic effect of $B . d ., \Phi_{i}$ values remain at the low level in the years following the die-off year (Fig. 1A). Each of the

\footnotetext{
s $\langle$ http:/iwww.ncde.noaa.gov/oa/ncdc.html $\rangle$

" (http://www.co.nres.usda.gov $\rangle$
}

16 year $\times$ population combinations was modeled with an acute and chronic effect of $B . d$. Thus, there were 32 models of $B . d$. in the set of candidate models.

Hypotheses and mathematical models of a marking effect. - The possibility that PIT tagging had deleterious effects on survival or that PIT tags were being lost was evaluated by comparing the survival rate of individuals PIT tagged for the first time in the current year (i.e., first-year captures) with individuals originally tagged in previous years (i.e., previous captures). Values of $\Phi_{i}$ for first-year captures will be lower than the $\Phi_{i}$ of previous captures if PIT tagging has a deleterious short-term effect on $\Phi_{i}$ or if PIT tags are quickly lost. Longer term marking effects (2-, 3- and 4-year) on $\Phi_{i}$ were also evaluated. For a 2-year marking effect, $\hat{\Phi}_{i}$ is expected to be lowest for first-year captures, intermediate for individuals that were tagged at the beginning of $i-1$, and highest for individuals that were tagged prior to $i-1$. It is important to note that this approach only allowed us to look for evidence of a pattern in the data that was consistent with tag loss or tag-induced mortality. This approach does not allow us to distinguish between the multiple mechanisms that may be responsible for the pattern.

Standard models. - The candidate set of models of $\Phi_{i}$ contained other, more standard, effects. Notation of these effects follows that of Lebreton et al. (1992). Time-dependent models (symbolized by " $t$ " in the model description) and time-invariant models (symbolized by ".," in the model description) of $\Phi_{i}$ were included in the set of candidate models. $\Phi_{i}$ were also modeled as quadratic and linear functions of time. Finally, $\Phi_{i}$ were modeled using a population effect, symbolized by $g$ (i.e., separate estimates of $\Phi_{i}$ at KT and LL were included in these models). Additive and interactive effects between variables in a model are represented by "+" and "*" in model descriptions.

\section{Evaluation of models of capture probability}

A step-down approach was used in the analysis of capture probabilities (Lebreton et al. 1992). Each model of capture probability was first paired with the fully saturated model of $\hat{\Phi}_{i}$ in Program MARK. QAIC $c_{c}$ values were compared to determine which model best represented the data. The models of capture probability were evaluated a second time after the top model of $\hat{\Phi}_{i}$ was identified.

\section{GOF testing, model selection and parameter estimation}

Program MARK was used for goodness-of-fit testing, model selection, and parameter estimation. The most general C.JS model (i.e., the time $x$ site model) was first tested for goodness of fit using TEST2 and TEST3 in Program RELEASE (Lebreton et al. 1992).

We used $\triangle \mathrm{QAIC}_{\mathrm{c}}$ values and Akaike weights, $w_{i}$, to determine which model or set of models best described the information in the data and should be used for 
TABLE 2. Summaries of the capture-recapture data for (A) Kettle Tarn and (B) Lost Lake using $\mathrm{m}_{i j}$ arrays.

\begin{tabular}{|c|c|c|c|c|c|c|c|c|c|c|c|c|}
\hline \multirow{2}{*}{$\underset{i}{\text { Period }}$} & \multirow[b]{2}{*}{$R(i)$} & \multicolumn{11}{|c|}{ Sampling period $j$} \\
\hline & & 92 & 93 & 94 & 95 & 96 & 97 & 98 & 99 & 00 & 01 & Total \\
\hline \multicolumn{13}{|c|}{ A) Kettle Tarn (KT) } \\
\hline 91 & 25 & 1 & 3 & 6 & 0 & 0 & 0 & 0 & 0 & 0 & 0 & 10 \\
\hline 92 & 16 & & 6 & 4 & 2 & 0 & 0 & 0 & 0 & 0 & 0 & 12 \\
\hline 93 & 50 & & & 15 & 10 & 0 & 0 & 0 & 0 & 0 & 0 & 25 \\
\hline 94 & 115 & & & & 74 & 1 & 0 & 0 & 0 & 0 & 0 & 75 \\
\hline 95 & 188 & & & & & 15 & 1 & 0 & 0 & 0 & 0 & 16 \\
\hline 96 & 27 & & & & & & 0 & 0 & 0 & 0 & 0 & 0 \\
\hline 97 & 10 & & & & & & & 1 & 2 & 0 & 0 & 3 \\
\hline 98 & 13 & & & & & & & & 1 & 0 & 0 & 1 \\
\hline 99 & 11 & & & & & & & & & 1 & 1 & 2 \\
\hline 00 & 3 & & & & & & & & & & 0 & 0 \\
\hline \multicolumn{13}{|c|}{ B) Lost Lake (LL) } \\
\hline 91 & 189 & 59 & 18 & 2 & 7 & 2 & 0 & 0 & 0 & 0 & 0 & 88 \\
\hline 92 & 96 & & 26 & 17 & 9 & 0 & 1 & 0 & 0 & 0 & 0 & 53 \\
\hline 93 & 77 & & & 27 & 15 & 2 & 4 & 2 & 0 & 0 & 0 & 50 \\
\hline 94 & 105 & & & & 39 & 6 & 17 & 3 & 0 & 0 & 0 & 65 \\
\hline 95 & 121 & & & & & 22 & 30 & 15 & 0 & 0 & 0 & 67 \\
\hline 96 & 42 & & & & & & 24 & 6 & 0 & 0 & 0 & 30 \\
\hline 97 & 101 & & & & & & & 51 & 1 & 0 & 0 & 52 \\
\hline 98 & 102 & & & & & & & & 0 & 0 & 0 & 0 \\
\hline 99 & 1 & & & & & & & & & 0 & 0 & 0 \\
\hline 00 & 1 & & & & & & & & & & 0 & 0 \\
\hline
\end{tabular}

Note: $R_{i}$ is the number of individuals captured and released during sampling period $i ; \mathrm{m}_{i i}$ is the number of individuals captured during sampling period $i$ that are next captured at sampling period $j$.

inference. Both measures quantify the strength of evidence in support of a particular model as the "best" model in the candidate set of models (Burnham and Anderson 1998). The $\triangle \mathrm{QAIC}_{c}$ of any model $i$ in the candidate set is computed as $\mathrm{QAIC}_{\mathrm{c} i}-\mathrm{QAIC}_{\mathrm{c} \text { besi }}$. As $\triangle Q_{A I C}$ increases, the strength of evidence for a particular model gets smaller. A particular model's Akaike weight can be interpreted as the probability that this model is the "best" model, given the sampling situation at hand and that one of the models in the candidate set must be the "best" model (Burnham and Anderson 1998).

Fisher's method of maximum likelihood was used for estimation of parameters and their standard errors (Lebreton et al. 1992).

\section{RESULTS}

\section{Summary of raw data}

From 1991 to 2001,316 male boreal toads were captured 460 times at $\mathrm{KT}$ and 430 males were captured 835 times at LL (Table 2). Few of these captures were made from 1999 to 2001 , in spite of similar search effort. Only 16 toads were captured at KT and two toads at LL over those three years.

\section{Goodness-of-fit test}

Results of the goodness-of-fit test provided evidence of overdispersion in the data. The total $\chi^{2}$ test statistic was $44.89(\mathrm{df}=38)$. Thus, a variance inflation factor, $\hat{c}$, of $1.18\left(\chi^{2} / \mathrm{df}\right)$ was used.

\section{Analysis of capture probability}

The first analysis of the models of capture probability provided strong evidence that the top model was $p\left(g^{*} f\right)$. The Akaike weight of this model was $\sim 1$, which suggested that the other four models had no support in the data. The second evaluation confirmed these results and model $p\left(g^{*} t\right)$ was used in all models of apparent survival rate.

\section{Analyses of survival rates}

Survival models were evaluated in two steps. In the first step, each model was structured in Program MARK as just described and in Fig. 1 and the Appendix. The candidate model set had 32 B.d. models, 27 models with weather variables, five models of marking effect, and 25 models that contained standard effects. No models in the initial analysis combined the main effects of interest (i.e., B.d., weather, or marking effects).

Three results from step one suggested a second analysis. First, the top three models contained the marking effect and had combined Akaike weights $>0.88$. Second, only two of the top models contained environmental covariates and used fewer parameters. However, these two models had Akaike weights $\sim 0$. Third, two of the top three models contained time-varying estimates of $\Phi_{i}$ and were among the most highly parameterized models in the candidate set. Given the relative sparseness of the data, models that explained this apparent temporal variation in $\hat{\Phi}_{i}$ using fewer parameters were expected to have an advantage. These initial re- 
TABLE 3. Model-selection results from step two of the analysis; the top model from step one is the final model in the list.

\begin{tabular}{|c|c|c|c|c|c|}
\hline Model & QAIC $_{c}$ & $\triangle \mathrm{QAIC}_{\mathrm{c}}$ & $w_{i}^{\dagger}$ & $K \ddagger$ & QDeviance§ \\
\hline$\Phi$ (KT96, LL9S chytrid acute + marking effect) & 1950.51 & 0 & 0.43 & 23 & 1903.6 \\
\hline$\Phi$ (KT96, LL98 chytrid acute +2 -year marking effect) & 1952.04 & 1.53 & 0.20 & 23 & 1905.17 \\
\hline$\Phi(g+$ KT96, LL98 chytrid acute + marking effect $)$ & 1952.15 & 1.64 & 0.19 & 24 & 1903.2 \\
\hline$\Phi\left(g * \mathrm{~T}_{\min } 7\right.$-day + marking effect $)$ & 1954.14 & 3.63 & 0.07 & 25 & 1903.1 \\
\hline Ф (KT96, LL98 chytrid acute + 3-year marking effect) & 1955.16 & 4.65 & 0.04 & 23 & 1908.3 \\
\hline$\Phi$ (KT95, LL98 chytrid chronic + marking effect) & 1956.61 & 6.10 & 0.02 & 23 & 1909.7 \\
\hline$\Phi$ (KT96, LL98 chytrid acute + 4-year marking effect) & 1957.78 & 7.26 & 0.01 & 23 & 1910.9 \\
\hline$\Phi(g+K T 95$. LL98 chytrid chronic + marking $\mathrm{effect})$ & 1958.41 & 7.90 & $<0.01$ & 24 & 1909.5 \\
\hline$\Phi$ (KT96, LL98 chytrid chronic + marking effect) & 1959.50 & 8.99 & $<0.01$ & 23 & 1912.6 \\
\hline$\Phi(g * t+$ marking effect $)$ & 1965.45 & 14.94 & $<0.001$ & 39 & 1885.0 \\
\hline
\end{tabular}

Note: Only the models of apparent survival rate are shown. The model of capture probability was $p(g * t)$ in every case. $\dagger$ Akaike weights, $w_{j}$, do not sum to 1 because models with $\triangle Q_{\text {AIC }}$ values $>10$ are not included.

¥ Number of separately identifiable parameters.

$\S$ Deviance $=-2 \times[\log$-likelihood $(\hat{\Phi})] / \hat{c}$.

sults indicated that the marking effect was important to the modeling of survival rate estimates. The lack of support for more specific models (those that modeled the temporal variation in $\Phi_{i}$ using environmental covariates) may have been a consequence of the strength of the marking effect and not the inadequacy of weather and disease as explanatory covariates. The estimate of the marking effect (on the logit scale) from the top model was strongly negative $\left(\hat{\beta}_{\text {mark }}=-1.29 ; 95 \% \mathrm{cl}\right.$ $=-1.85$ to -0.74 )

In step two, we incorporated the marking effect into each model in the original candidate set, because we expected that this would allow more parsimonious and informative modeling of the temporal variation in estimates of $\Phi_{i}$. Model selection results from step two were consistent with this expectation (Table 3). The top model from step one now had virtually no Akaike weight. The new top model represented the hypothesis of an introduced $B . d$. as the cause of the declines. The top model showed an acute decline in the estimate of $\Phi_{i}$ in 1996 at KT and in 1998 at LL. Two other models with relatively high Akaike weights also had support in the data (Burnham and Anderson 1998). Additional evidence, however, suggests that these models are competitive only because of their similarity to the top model.

The second-ranked model (Table 3 ) is identical to the top model except that it contains a 2 -year marking effect. This model makes apparent survival rate in a particular year a linear function of the number of years since an individual was tagged and, as such, estimates the 1 - and 2-year marking effects with a single regression coefficient. In the presence of a strong 1-year marking effect, this model structure could suggest a 2year marking effect that is an artifact of the 1-year effect. To evaluate this possibility, we modeled the 1 and 2-year effects separately. The estimate of slope parameter for the 1 -year marking effect, $\hat{\beta}_{\text {mark }}$, was $-1.13(95 \% \mathrm{CI}=-1.6$ to -0.67$)$. However, the estimate of the slope parameter on the 2-year effect, $\hat{\beta}_{2 \text {-mark }}$, was -0.087 and its $95 \%$ CI was nearly centered on 0 . This result suggested that the 2-year effect was not an important addition to the top-ranked model. Additional evidence of the lack of importance of the 2year effect came from the $\triangle \mathrm{QAIC}_{\mathrm{c}}$ of the model. Because this model had one additional parameter, one would expect it to have a $\triangle \mathrm{QAIC}=2.08$, if it provided no improvement in fit compared to the top model. The model's $\triangle Q_{A I C}$ value $=2.04$ (Table 3 ), which suggests that it provided very little improvement in fit. Similar analyses showed that the 3-and 4-year marking effects were also unimportant. The third-ranked model (Table 3) also had substantial support. This model was identical to the top model, except that it included a population effect: survival rates at KT were expected to be higher than those at LL because $\mathrm{KT}$ is at a lower elevation, where weather conditions are not as widely variable. However, this model included one additional parameter with an expected $\triangle Q A I C_{c} \approx 2.08$ if it provided no improvement in fit. The $\triangle \mathrm{QAIC}$. of this model was 1.64 , which suggests only a marginal improvement in fit. The estimate of the slope parameter on the site effect $\left(\hat{\beta}_{\text {site }}=0.15,\left[\operatorname{sE}\left(\hat{\beta}_{\text {site }}\right)=0.23\right]\right)$ had a $95 \% \mathrm{CI}$ that considerably overlapped zero. When these models were removed from the analysis, the Akaike weight of the top model was $>0.77$ and was $>6$ times the Akaike weight of the second-ranked model. These values suggest that there is considerable support for the topranked model in the data. However, Anderson et al. (2001) recommend that the variance component due to model selection uncertainty be included in estimates of precision for Akaike weights $<0.9$. Consequently, model averaging was used to generate estimates of $\Phi_{i}$ and their precision (Fig. 2; Burnham and Anderson 1998).

The top model contained two effects on $\Phi_{i}$ : a marking effect and an acute effect of B.d. The estimate of the marking effect $\left(\hat{\beta}_{\text {mark }}=-1.12 ; 95 \% \mathrm{CI}=-1.55\right.$ to -0.68 ) suggested that apparent survival in the first year following capture was much lower than in subsequent years. The estimate of the slope parameter for the acute chytrid effect in the top model, $\hat{\beta}_{B . d}$, was $-6.40(95 \%$ $\mathrm{CI}=-7.9$ to -4.8 ), providing strong evidence of reduced $\hat{\Phi}_{i}$ in 1996 at KT and in 1998 at LL. Estimates 


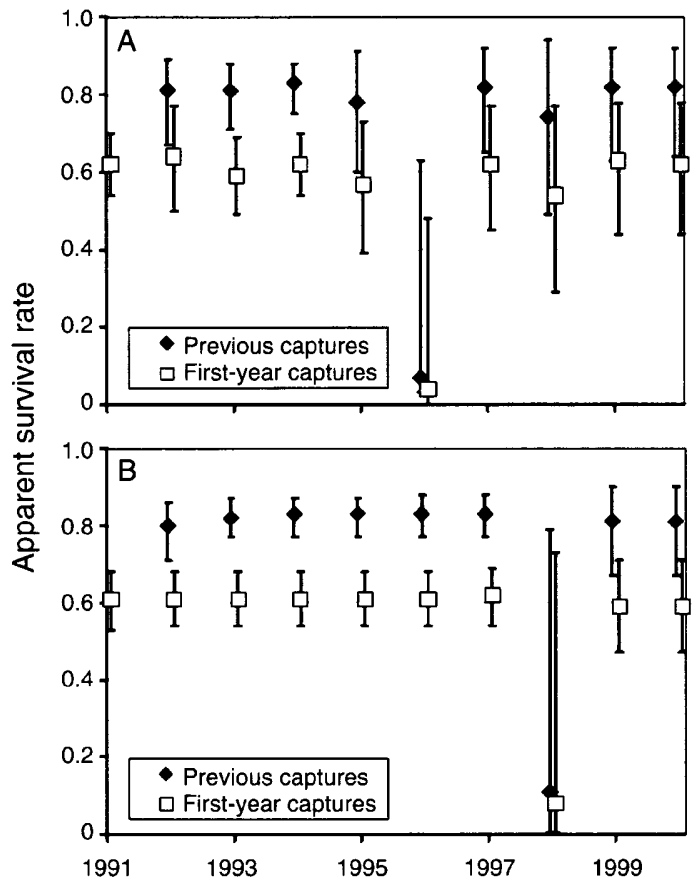

FIG. 2. (A) Model-averaged $\hat{\Phi}_{i}$ for first-year captures (open squares) and previous captures (solid diamonds) at Kettle Tarn (KT). Note the considerable decline in $\hat{\Phi}$ in 1996 for both previous and first-year captures. (B) Model-averaged $\hat{\Phi}_{i}$ for first-year captures (open squares) and previous captures (solid diamonds) at Lost Lake (LL). Note the considerable decline in $\hat{\Phi}$ in 1998 for both previous and first-year captures. In both figures, $\hat{\Phi}_{i}$ of first-year captures is lower than $\hat{\Phi}_{i}$ of previous captures. Error bars represent $95 \%$ confidence intervals.

of the slope parameters for the marking and disease effects were similar across the top four models.

Model-averaged estimates of $\Phi_{i}$ are presented (Fig. $2)$. For the KT population, $\hat{\Phi}_{j}$ for previous captures ranges from 0.76 to 0.83 in all years in which a presumed die-off from chytrid fungus did not occur ( $\mathrm{SE}\left[\hat{\Phi}_{i, \mathrm{prev}}\right]$ ranged from 0.03 to 0.14 ) and is much lower in 1996 , the presumed year of the die-off $\left(\Phi_{19 \% 6 \mathrm{prev}}=\right.$ $0.06 ; 95 \% \mathrm{Cl}=0.003-0.58$ ). For first-year captures at $\mathrm{KT}$, $\hat{\Phi}_{i}$ ranged from 0.56 to 0.64 in years in which a presumed die-off from chytrid fungus did not occur ( $\mathrm{SE}\left[\hat{\Phi}_{i, \text { first }}\right]$ ranged from 0.04 to 0.12 ) and is much lower in $1996\left(\hat{\Phi}_{i, \text { frrs }}=0.03 ; 95 \% \mathrm{Cl}=0.001-0.44\right)$. Modelaveraged estimates of $\Phi_{i}$ and their standard errors for the LL population were nearly identical to those for the KT population. The apparent year of the die-off at LL, however, was 1998.

The models that incorporated weather variables had little or no support in the data. The top weather model was $\Phi\left(g * T_{\min }\right.$ coldest 7 days + first year capture $)$. The $\Delta \mathrm{QAIC}_{\mathrm{c}}$ value and $\mathrm{QAIC}_{\mathrm{c}}$ weight of this model suggest that it provides a much poorer description of the data than the top-ranked model $\left(\Delta \mathrm{QAIC}_{\mathrm{c}}\right.$ value $=3.63$ and
QAIC $_{c}$ weight $=0.07$; Table 3 ). No other weather model had an Akaike weight $>0.01$.

\section{Additional exploratory analyses}

Two additional, exploratory analyses of apparent survival rates were also performed. These analyses evaluated: (1) additional models of the long-term effect of $B . d$. on apparent survival rates, and (2) models that incorporated weather variables into the top model (Table 3$)$.

Two additional models of the long-term effect of $B . d$. were evaluated. These models were intermediate to the acute and chronic effects previously described. After the decline year, the "slope" model allowed survival rates to return to pre-decline levels in a linear fashion over three years (Fig. 1B). The "post-die-off" model allowed survival rates after the year of the die-off to be different than they were prior to and during the year of the die-off (Fig. 1B). This model allows for the possibility that survival rates after the die-off are intermediate to survival rates before and during the dieoff. The post-die-off model had one more parameter than the slope, chronic, and acute effect models.

For each of the 16 year $\times$ population combinations, we used the slope and post-die-off forms to model the long-term effect of the chytrid fungus on survival rates. Neither of these alternate forms performed better than the top model from Table 3, although the post-die-off form had strong support in the data. The model with the die-off year at KT in 1996 and at LL in 1998 and the post-die-off form of the long-term effect had an Akaike weight of 0.11 . The estimate of apparent survival rate for the years after the die-off, $\hat{\Phi}_{i, \text { post-die }}$, is 0.49 $(95 \% \mathrm{CI}=0.26-0.72)$. Models with the slope form of the long-term effect had little support.

The second exploratory analysis incorporated weather variables into the top disease model. Upon completion of the a priori analysis, it was clear that the strong disease effect in the top model may be masking evidence of a correlation between weather variables and $\hat{\Phi}_{i}$. The purpose of this exploratory analysis was to look for evidence of an additive effect of weather variables on $\hat{\Phi}_{i}$. Each of the models in this analysis included the marking effect, the acute disease effect in 1996 at KT and 1998 at LL, and one of the weather variables (Table 1). Models that included the weather variables " $T_{\min }$ coldest 7 days" and "Growing season length" were slight improvements over the previous top model (Table 3). The $\mathrm{QAIC}_{\mathrm{c}}$ values of the models with " $\mathrm{T}_{\min }$ coldest 7 days" and "Growing season length" were 0.64 and 0.51 units lower than the previous top model. The estimate of the slope parameter $\beta_{\mathrm{T}-\text { min days }}=0.28$ $(95 \% \mathrm{CI}=-0.05$ to 0.62$)$. Though this estimate slightly overlaps zero, it provides evidence of higher survival rates over winters with higher minimum temperatures. The estimate of the slope parameter $\beta_{\text {grow }}=0.76(95 \%$ $\mathrm{CI}=-0.21$ to 1.73 ), which suggests higher survival rates in years that follow long growing seasons. These 
results were consistent with a priori predictions of the relationship between these weather variables and survival rates (Table 1).

\section{Discussion}

Muths et al. (2003) provided evidence for B.d. as the proximate cause of declines in boreal toad populations at Kettle Tarn and Lost Lake, but other explanatory hypotheses of population decline were not evaluated. For example, the potential role of weather variables was not examined using the data from these populations, although climate change has been implicated in declines and extinctions in other amphibian populations (e.g., Pounds et al. 1999) and has become a more commonly cited cause of amphibian population declines (Stuart et al. 2004). Our results provide strong support for the hypothesis of an introduced $B . d$. as the cause of the declines and little support for models that included weather variables.

The temporal and spatial variation in model-averaged estimates of apparent survival rates were consistent with what one would expect under the scenario of an introduced, highly virulent pathogen. Although we lack unequivocal evidence that $B . d$. was recently introduced at KT and LL, ecological and genetic evidence suggest that $B . d$. recently has been introduced into many countries (Daszak et al. 1999, Morehouse et al. 2003). The top model had strong support in the data ( $>77 \%$ of the QAIC $_{c}$ weight). Five additional insights provided by these analyses are as follows.

1. Estimates of $\Phi_{i}$ were more than one order of magnitude lower in the year of the declines than in other years.-Model-averaged estimates of $\Phi_{i}$ in the years of the decline were $<0.10$ and were consistent with estimated survival rates from other amphibian populations that experienced mass die-offs attributed to $B . d$. For example, Berger et al. (1998) estimated that the survival rate in an infected, captive population of rain forest frogs (Mixophyes fasciolatus) was $<0.10$. These authors also reported that some of the species observed before mass die-offs in Australia and Central America have not been seen subsequently (see also Lips 1999). If one assumes adequate searching, that observation suggests low survival rates in those species. Survival rates from some laboratory studies have also been very low $(0 \%$ in many cases; [Berger et al. 1998, 1999, 2004, Longcore et al. 1999]), including studies involving boreal toads (C. Carey and L. Livo, unpublished data). Conversely, other studies have reported higher survival rates for infected amphibians. Berger et al. (2004) observed higher survival rates in infected $M$. fasciolatus exposed to higher air temperatures. Retallick et al. (2004) reported quarterly survival rates for infected Eungella torrent frogs (Taudactylus eungellensis) that ranged from $\sim 0.20$ to 0.95 .

2. The temporal duration of the effect of the disease on estimates of survival rates may be short.--From the top model (Table 3 ), $\hat{\Phi}_{i}$ are suppressed for only a single interval. Subsequent to the die-off, $\hat{\Phi}_{i}$ return to earlier levels. S. M. Blomquist and M. J. Sredl (unpublished manuscript) reported in 2001 a similar temporal pattern in their data on Rana yavapaiensis. Daszak et al. (1999) hypothesized that this pattern could be caused by reduced transmission rates as host densities decline or by the existence of a few resistant individuals in the host population. An exploratory analysis of other forms of the long-term effect of $B . d$. on apparent survival rates provided support for the post-die-off form. Little evidence was found for the chronic and the slope forms of the long-term effect. Inferences about long-term effect of $B . d$. on survival rates should be made with considerable caution, however. Selection of a model of the long-term effect of $B . d$. was based on few data. After 1996 , only 27 captures were made at KT, and only two captures were made after 1998 at LL.

3. An acute (i.e., 1-year) effect of narking on $\hat{\Phi}_{i}$ was apparent.-The $\hat{\Phi}_{i}$ of first-year captures is $\sim 20$ per-

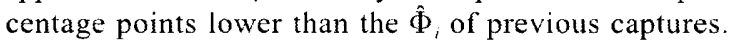
This effect has several possible explanations. Several authors have reported PIT tag loss in a variety of taxa (e.g., Schooley et al. 1993). However, Brown (1997) found no evidence of short-term PIT tag loss in laboratory and field experiments involving amphibians (Rana temporaria and Bufo bufo). In addition to tag loss, the difference between the survival rates of firstyear and previous captures could be caused by shortterm, deleterious effects of the PIT tag or tagging process (Green and Kagarise Sherman 2001) or differential survival rates between younger (first-year captures) and older toads (previous captures). Other mechanisms (e.g., capture probability heterogeneity) could also be responsible for the observed marking effect.

4. Temporal variance.-Cycles in the demographic parameters of amphibian populations are often characterized as boom-or-bust, with large variability in abundance caused by highly variable adult survival and/or recruitment rates. Yet, the top-ranked model from this analysis and the model-averaged estimates of survival rate suggest low temporal variance. Based on two types of life history sensitivity analyses, Biek et al. (2002) concluded that postmetamorphic survival rates (i.e., juvenile and adult survival) had the strongest effect on population growth rates in Bufo boreas. Vonesh and De la Cruz (2002) incorporated density-dependent effects into a similar analysis and also found that postmetamorphic survival rates had the largest effect on population growth rates. Pfister (1998) suggested that demographic parameters that have a relatively strong effect on population growth should have relatively low variance. Therefore, annual survival rates in a viable boreal toad population are expected to show little year-to-year variability. The results of this analysis support that expectation. High temporal variability in annual survival rate may only be brought about by extreme environmental conditions (e.g., the introduction of a novel pathogen). 
5. Weather effects.--Although there was little evidence to suggest that weather conditions at KT and LL were responsible for the decline, an exploratory analysis of the data provided evidence that temporal variation in the survival rates of boreal toads is positively correlated with winter air temperature and the length of the previous growing season. Anholt et al. (2003) also reported that survival rates in two populations of Rana lessonae and $R$. esculenta were higher over winters with less extremely low temperatures.

\section{Other possible causes}

Other possible causes of the declines at KT and LL have not been evaluated. For example, authors have shown detrimental effects of UV-B radiation on demographic parameters of amphibians (e.g., Blaustein et al. 1994). Although Corn (1998) found no evidence of a detrimental effect of UV-B radiation on boreal toad embryos at KT and LL, negative effects of UV-B on adults remain a possibility. Researchers have also implicated acidification of habitats in the declines in amphibian populations (Harte and Hoffman 1989). Corn and Vertucci (1992) concluded that habitat acidification posed little risk to embryos of six species of amphibians in the mountains of Colorado, including $B$. boreas. Other environmental factors (e.g., chemical pollutants, predation) also may have played a role in these declines, either as direct causes of mortality or through interactions with other environmental factors.

\section{Long-term viability of boreal toads at Kettle Tarn and Lost Lake}

Observations from recent field seasons suggest low viability over the long term for the populations of $B$. boreas at KT and LL. Few adults were observed during capture sessions in the breeding seasons of 2002 and 2003. Three adult males and as many as seven adult females have been observed at KT, and only two adult females have been observed at LL (E. Muths, unpublished data). No evidence of reproduction has been observed at $L L$ in recent years. Even though more than five years have passed since the declines, the sizes of the adult populations at these sites appear to remain small. Green and Kagarise Sherman (2001) noted that a montane population of Bufo canorus in California, in which B.d. had been confirmed, has not recovered from declines that occurred in the early $1980 \mathrm{~s}$.

In addition, recent years of below-average precipitation have resulted in drought conditions in many parts of the western United States. Kettle Tarn completely dried in 2002, 2003, and 2004, as have many of the pools around Lost Lake that boreal toads once utilized. These conditions have not been observed in 10 years (P. S. Corn and E. Muths, personal observation), and probably increase the level of stress that these small populations are experiencing.

On the other hand, observations of reproduction and metamorphosis in the boreal toads at KT in 2002 and
2003 (E. Muths, unpublished data) are reasons for optimism. However, life history characteristics of $B$. boreas (i.e., 3-4 years from metamorphosis to adulthood) mean that it may be several years before the long-term viability of the populations of boreal toads at $\mathrm{KT}$ and LL can be assessed.

\section{ACKNOWLEDGMENTS}

We thank Gary White and Tom Hobbs for their contributions. We also thank the many people who assisted with fieldwork. Ryan Monello, Tim Phillips, Terry Terrell, and Matt Wilber at Rocky Mountain National Park provided logistic and field support. Nolan Doesken at the Colorado Climate Center and Mike Gillespie and Mary Vigil at the Natural Resources Conservation Service provided advice on the use of weather station data. Three reviewers provided valuable feedback on an earlier draft of this paper. Funding for this work was provided by the U.S. Geological Survey's Fort Collins Science Center and Amphibian Research and Monitoring Initiative (ARMI) and the U.S. Environmental Protection Agency's Science to Achieve Results Program (Grant \# R827449-01-0)

\section{Literature Cited}

Anderson, D. R., W. A. Link, D. H. Johnson, and K. P. Burnham. 2001. Suggestions for presenting the results of data analyses. Journal of Wildlife Management 65:373-378.

Anholt, B. R., H. Hotz, G.-D. Guex, and R. D. Semlitsch. 2003. Overwinter survival of Rana lessonae and its hemiclonal associate Rana esculenta. Ecology 84:391--397.

Berger, L., et al. 1998. Chytridiomycosis causes amphibian mortality associated with population declines in the rain forests of Australia and Central America. Proceedings of the National Academy of Sciences (USA) 95:9031-9036.

Berger. L., et al. 2004 Effect of season and temperature on mortality in amphibians due to chytridiomycosis. Australian Veterinary Journal 82:434--439.

Berger, L., R. Speare, and A. Hyatt. 1999. Chytrid fungi and amphibian declines: overview, inplications and future directions. Pages 23-33 in A. Campbell, editor. Declines and disappearances of Australian frogs. Environment Australia, Canberra, Australia.

Biek, R., W. C. Funk, B. A. Maxell, and L. S. Mills. 2002 What is missing in amphibian decline research: insights from ecological sensitivity analysis. Conservation Biology 16:728-734.

Blaustein, A. R., P. D. Hoffman, D. G. Hokit, J. M. Kiesecker. S. C. Walls, and J. B. Hays. 1994. UV repair and resistance to solar UV-B in amphibian eggs: a link to population declines? Proceedings of the National Academy of Sciences (USA) 91:1791-1795.

Brown, L. J. 1997. An evaluation of some marking and trapping techniques currently used in the study of anuran population dynamics. Journal of Herpetology 31:410-419.

Burnham, K. P., and D. R. Anderson. 1998. Model selection and inference: a practical information-theoretic approach. Springer-Verlag, New York, New York, USA.

Campbell, J. B. 1970. Hibernacula of a population of Bufo horeas boreas in the Colorado Front Range. Herpetologica 26:278-282.

Carey, C., P. S. Corn, M. S. Jones, L. J. Livo, E. Muths, and C. W. Loeffler. 2005 . Factors limiting the recovery of boreal toads (Bufo b. boreas). Pages 222-236 in M. Lannoo, editor. Amphibian declines: the conservation status of United States species. Volume 1. Conservation essays. University of California Press, Berkeley, California, USA.

Carey, C., W. R. Heyer, J. Wilkinson, R. A. Alford, J. W. Arntzen, T. Halliday, L. Hungerford, K. R. Lips, E. M. Middleton, S. A. Orchard, and A. S. Rand. 2001. Am- 
phibian declines and environmental change: use of remotesensing data to identify environmental correlates. Conservation Biology 15:903-913.

Corn. P. S. 1998 . Effects of ultraviolet radiation on boreal toads in Colorado. Ecological Applications 8:18-26.

Corn. P. S., M. L. Jennings, and E. Muths. 1997. Survey and assessment of amphibian populations in Rocky Mountain National Park. Northwestern Naturalist 78:34-55.

Corn, P. S., and F. A. Vertucci. 1992. Descriptive risk assessment of the effects of acidic deposition on Rocky Mountain amphibians. Journal of Herpetology 26:361-369.

Daszak, P.. L. Berger, A. A. Cunningham, A. D. Hyatt, D. E. Green, and R. Spear. 1999. Emerging infectious diseases and amphibian population declines. Emerging Infectious Diseases 5:735-748.

Duellman, W. E., and L. Trueb. 1994. Biology of amphibians Johns Hopkins University Press, Baltimore, Maryland, USA.

Green, D. E., and C. Kagarise Sherman. 2001. Diagnostic histological findings in Yosemite toads (Bufo canorus) from a die-off in the 1970s. Journal of Herpetology 35:92-103.

Hammerson, G. A. 1999. Amphibians and reptiles in Colorado: a Colorado field guide. Second edition. University of Colorado Press, Niwot, Colorado, USA.

Harte, J., and E. Hoffman. 1989. Possible effects of acidic deposition on a Rocky Mountain population of the tiger salamander Ambystoma tigrinum. Conservation Biology 3: $149-158$.

Houlahan, J. E., C. S. Findlay. B. R. Schmidt, A. H. Meyer and S. L. Kuzmin. 2000. Quantitative evidence for global amphibian declines. Nature 404:752-755.

Lebreton, J.-D., K. P. Burnham, J. Clobert, and D. R. Anderson. 1992. Modeling survival and testing biological hypotheses using marked animals: a unified approach with case studies. Ecological Monographs 62:67-118.

Lips, K. R. 1999. Mass mortality and population declines of anurans at an upland site in western Panama. Conservation Biology 13:117-125

Longcore, J. E., A. P. Pessier. and D. K. Nichols. 1999. Batrachochytrium dendrobatidis gen. et sp. nov., a chytrid pathogenic to amphibians. Mycologia 91:219-227.

Morehouse, E. A., T. Y. James, A. R. D. Ganley, R. Vilgalys, L. Berger, P. J. Murphy, and J. E. Longcore. 2003. Multilocus sequence typing suggests the chytrid pathogen of amphibians is a recently emerged clone. Molecular Ecology 12:395-403

Murray, D. L., and M. R. Fuller. 2000. A critical review of the effects of marking on the biology of vertebrates. Pages
15-64 in L. Boitani and T. K. Fuller, editors. Research techniques in animal ecology: controversies and consequences. Columbia University Press, New York, New York, USA.

Muths, E., P. S. Corn, A. P. Pessier, and D. E. Green. 2003. Evidence for disease-related amphibian decline in Colorado. Biological Conservation 110:357-365.

Olson, D. H. 1992. Ecological susceptibility of amphibians to population declines. Pages 55-62 in R. R. Harris and D. E. Erman, technical coordinators, and H. M. Kerner, editor. Proceedings of the Symposium on Biodiversity of Northwestern California. Report 2. Davis, California, USA. University of California Wildland Resources Center. Davis, California, USA.

Pfister, C. A. 1998. Patterns of variance in stage-structured populations: evolutionary predictions and ecological implications. Proceedings of the National Academy of Sciences (USA) 95:213-218.

Pounds, J. A., M. P. L. Fogden, and J. H. Campbell. 1999. Biological response to climate change on a tropical mountain. Nature 398:611-615.

Retallick. R. W. R., H. McCallum, and R. Speare. 2004. Endemic infection of the amphibian chytrid fungus in a frog community post-decline. PLoS Biology 2(11):e351 (www.plosbiology. org) [doi: 10.1371/journal pbio. 0020351]

Scherer, R. D. 2004. An evaluation of weather and introduced disease as causes of decline in two populations of boreal toads in Rocky Mountain National Park: an informationtheoretic approach. Thesis. Colorado State University, Fort Collins, Colorado, USA.

Schooley, R. L., B. Van Horne, and K. P. Burnham. 1993. Passive integrated transponders for marking free-ranging Townsend's ground squirrels. Journal of Mammalogy 74: $480-484$.

Stuart, S. N., J. S. Chanson, N. A. Cox, B. E. Young, A. S. L. Rodrigues, D. L. Fischman, and R. W. Waller. 2004. Status and trends in amphibian declines and extinctions worldwide. Science 306:1783-1786. (www.sciencexpress.) [doi: 10.1126/science. 1103538 ]

Vonesh, J. R., and O. De la Cruz. 2002. Complex life cycles and density dependence: assessing the contribution of egg mortality to amphibian declines. Oecologia 133:325-333.

White, G. C., and K. P. Burnham. 1999. Program MARK: survival estimation from populations of marked animals. Bird Study 46(Supplement): $120 \cdots 130$

Williams, B. K., J. D. Nichols, and M. J. Conroy. 2002. Analysis and management of animal populations. Academic Press, San Diego, California, USA

\section{APPENDIX}

Descriptions of each weather variable, information on the weather stations and the methods used to derive estimates of weather conditions at Kettle Tarn (KT) and Lost Lake (LL), and a complete list of the weather models in the candidate set are available in ESA's Electronic Data Archive: Ecological Archives A015-067-A1 